\title{
COMPARATIVE ANALYSIS OF THE USE OF FINE NEEDLE ASPIRATION IN THE DIFFERENTIAL DIAGNOSIS OF BREAST NODES IN THE STATE OF GOIÁS
}

Fernando C. Silva1, Edison B. L. B. Junior¹, Cassiano S. Coutinho¹, Rayssa F. Silva¹, Rayssa O. Glória', Fabiana C. Q. S. Anjos', Vantuir J. D. Mota', Priscila F. Barbosa'

${ }^{1}$ Centro Universitário UNIRG - Gurupi (TO), Brazil.

Objective: To analyze the result of fine needle aspiration (FNA) according to the most prevalent types of nodules in malignant cases, considering the color/race and the age bracket of the patients. Methodology: A cross - sectional study based on data collected in the Breast Cancer Information System (SISMAMA) - from Information Technology Department of the Brazilian Public Health Care System (DataSus) based on data from cytopathological breast exams realized by Fine Needle Aspiration (FNA) performed in the State of Goiás in the period from February 2012 to February 2014. The present study comprised the following age groups: 25-29; 30-34; 35-39; 40-44; 45-49; 50-54; 55-59; 60-64; 65-69; over 70 years old; in addiction to analyzing the prevalence of white, black and drab colors/races. Solid, cystic and solid-cystic nodules were studied. Results: In the analyzed period, 1052 exams were performed that detected breast nodules, of which $76.61 \%$ ( $\mathrm{n}=806)$ were solid, $11.21 \%$ ( $\mathrm{n}=118)$ cystic and $12.16 \%$ ( $\mathrm{n}=128)$ solid -cystic. Of total exams, $615(58.46 \%)$ were submitted to FNA and, through the results, the solid nodule presented the highest percentage of malignancy (5.85\%; $n=36)$. In the analysis of the patients diagnosed with this type of alteration, there was a predominance of drab color, totaling 230 cases (21.86\%). Taking into consideration their age group, it was observed that women between 40 and 49 years old were associated with a higher percentage of breast nodules $(27.33 \%)$, confirming statistical significance $(\mathrm{p}<0.05)$. Conclusion: The results of this study demonstrate that several women $(n=1052)$ in the state of Goiás were diagnosed with breast lumps according to the analyzed period, and more than half of this population (58.46\%) was submitted to the FNA. By assessing the types of nodules and those who most frequently show positivity for malignant processes, it was noticed that the solids correspond to this category, being that such alteration guided the present study for comparisons assessed later. The prevalence in terms of age range occurred in the fourth decade, confirming Brazilian society of Mastology statistics by saying that breast cancer occurs mainly after the age of 40 . With regard to the color/race, drab patients exhibit higher percentage of solid breast lumps. 